\title{
The genome of Dasychira pudibunda nucleopolyhedrovirus (DapuNPV) reveals novel genetic connection between baculoviruses infecting moths of the Lymantriidae family
}

\author{
Martyna Krejmer ${ }^{1}$, Iwona Skrzecz², Bartosz Wasag ${ }^{3}$, Boguslaw Szewczyk ${ }^{1}$ and Lukasz Rabalski ${ }^{1^{*}}$ (D)
}

\begin{abstract}
Background: DapuNPV (Dasychira pudibunda nucleopolyhedrovirus), presented in this report, belongs to Alphabaculovirus group Ib. Its full, newly sequenced genome shows close relationship to baculovirus OpMNPV isolated from douglas-fir tussock moth Orgyia pseudotsugata. Baculovirus DapuNPV is a natural limiter of pale tussock moth Dasychira pudibunda L. (syn. Calliteara pudibunda L.)(Lepidoptera, Lymantriidae), which can occur in a form of an outbreak on many species of deciduous trees and may cause significant economic losses in the forests.

Methods: Late instars dead larvae of pale tussock moth were mechanically homogenized and polyhedra were purified during series of ultracentrifugation. Viral DNA was extarcted and sequenced using Miseq Illumina platform. 294,902 paired reads were used for de novo assembling. Genome annotation, multiple allingment to others baculoviruses and phylogegentic analises were perform with the use of multiple bioinformatic tools like: Glimmer3, HMMER web server, Geneious 7 and MEGA6.

Results: The genome of DapuNPV is 136,761 bp long with AT pairs content $45.6 \%$. The predicted number of encoded putative open reading frames (ORFs) is 161 and six of them demonstrate low or no homology to ORFs previously found in baculoviruses. DapuNPV genome shows very high similarity to OpMNPV in a nucleotide sequence ( $91.1 \%$ of identity) and gene content (150 homologous ORFs), though some major differences (e.g. lack of he65 in OpMNPV) have also been noted.

Conclusions: Similarly to other members of the Baculoviridae family, DapuNPV baculovirus possesses highly conserved core genes. Among them, there is a second copy of occluded derived virus envelope 27 protein (odv-e27), which was previously found only in a member of Alphabaculovirus group II - LyxyMNPV (Lymantria xylina MNPV). Surprisingly enough, DapuNPV and LyxyMNPV genomes share also another feature. Phylogenetic analysis of chitin binding family protein (cbpl) indicates significant similarity of those two baculoviruses from distinct evolutionary groups which infect the same hosts from Lymantriidae. The ubiquitin like family gene (ubi), which has not been described until now, is another characteristic component of DapuNPV genome.
\end{abstract}

Keywords: Baculovirus, Next generation sequencing, DapuNPV, Pale tussock moth, Dasychira pudibunda, OpMNPV

\footnotetext{
* Correspondence: lukasz.rabalski@biotech.ug.edu.pl

'Department of Recombinant Vaccines, Intercollegiate Faculty of

Biotechnology University of Gdansk and Medical University of Gdansk, 80-822

Gdansk, Kladki Str. 24, Poland

Full list of author information is available at the end of the article
} 


\section{Background}

The Baculoviridae family is a major group of viruses infecting insects. Its members are enveloped, rod-shaped viruses with covalently closed, circular, double-stranded DNA $[1,2]$. The genome size ranges between $81,755 \mathrm{kbp}$ (NeleNPV, Neodiprion lecontei nucleopolyhedrovirus [3]) and 178,733 bp (XcGV, Xestia c-nigrum granulovirus [4]). It has been reported that the Baculoviridae family contains 37 core genes [5].

Based on morphology, Baculoviridae family was originally subdivided into two genera: nucleopolyhedroviruses (NPV) forming polyhedral occlusion bodies (OBs) with single or multiple virions inside, and granuloviruses (GV) with single virions inside ovoid OBs made of granulin [6-8]. In 2006, based on genetic sequences and due to host-associated virus evolution new classification was proposed. According to this nomenclature, the family was divided into: Alphabaculovirus (lepidopteran-specific NPVs), Betabaculovirus (lepidopteran-specific GVs), Gammabaculovirus (hymenopteran-specific NPVs) and Deltabaculovirus (dipteran-specific baculoviruses with only one representative Culex nigripalpus nucleopolyhedrovirus (CuniNPV)) [8-10]. Alphabaculovirus genus consists of group I and II, depending on the presence or absence of BVs envelope glycoprotein gp64. Only the members of group I contain gp64, while gene encoding fusion protein (F) indicates affiliation to group II (as well as Beta- and Deltabaculoviruses) [11-14]. It is suggested that group I originated from ancestral group II of Alphabaculovirus [15].

During the life cycle of the virus two different virion phenotypes are observed: occlusion derived virus (ODV) and budded virions (BV). The first one is responsible for spreading infection between caterpillars, while the second one for cell-to-cell propagation inside a larvae [1, 2]. The members of all Baculoviridae family produce ODV, while BV is produced only by three genera: Alpha-, Beta- and Deltabaculovirus [16].

The pale tussock moth Dasychira pudibunda L. (syn. Calliteara pudibunda L.) (Lepidoptera, Lymantriidae) is a frequent defoliator with economic significance. Larvae prefer mainly deciduous trees, especially Fagus spp., but they can feed on many different plant species like: Quercus, Betula, Corylus, Tilia, Juglans, Salix, Populus, fruit trees and shrubs in orchards as well; very rarely on conifers $[17,18]$. This pest is present in the entire Europe except for Far North, but causes outbreaks only in the area of western and central part of the continent (between 48th and 57th parallels) [19]. Since 1810, massive infestations have been reported mainly in Germany [20, 21], Sweden [22-24] and Denmark [25] - all on Fagus trees. In central-eastern Europe in countries such as Poland, Romania and Ukraine, the main host plant during outbreaks was Quercus robur L. [21, 26]. Dasychira pudibunda L. occurs also in central Asia, China and Japan. Infected larvae used in these studies were collected in 2010 in Northern part of Poland from 50-year Fagus sylvatica L. trees growing in the State Forest. At present, this pest is relatively rare in Poland and does not cause problems in forests [27].

One of the agent that is able to control mass occurrence of the pale tussock larvae is a baculovirus. Viral disease which often cause epizootic are responsible for long protection of trees against reestablishment of a pest, therefore the baculovirus is an environmental friendly biopesticide [28]. Although the existence of Dasychira pudibunda nucleopolyhedrovirus (DapuNPV) has been occasionally reported in the literature [29], so far there is no genome sequence available in the National Center for Biotechnology Information (NCBI) database. Here, we report the first full genome sequence of this baculovirus, that shows its close relation to Orgyia pseudotsugata MNPV (OpMNPV), Choristoneura murinana MNPV (ChmuMNPV), Choristoneura rosaceana MNPV (ChroMNPV) and Choristoneura fumiferana MNPV (CfMNPV).

\section{Results and discussion}

\section{General characteristics of the DapuNPV genome}

The complete circular DapuNPV genome is 136,761 base pairs long (Fig. 1). It is 4,766 bp longer than the genome of the most closely related baculovirus OpMNPV. Between DapuNPV and OpMNPV there is $91.1 \%$ similarity in nucleotide sequence based on whole genome MAFT alignment. The AT pairs content is $45.6 \%$ and classifies DapuNPV in the vicinity of OpMNPV with its $44.9 \%$, while the highest AT pairs content among the members of Baculoviridae family is found in CrleGV (Cryptophlebia leucotreta granulovirus) - $67.6 \%$ and the lowest in LdMNPV - $42.5 \%$. Intergenic regions of DapuNPV consist of 12,853 bp $(9.4 \%$ of whole genome) with AT pairs content calculated to be $59.8 \%$.

The number of putative open reading frames (ORFs) in DapuNPV is equal to 161, nine more than in was annotated in OpMNPV genome (Additional file 1: Table S1). Two homologues to ORFs: dapu077 and dapu132 were not described in OpMNPV due to substitutions associated with changes in stop codons. From all DapuNPV ORFs found during homologue search using hidden Markov models analysis (HMMER) (see Methods) three had no hits (dapu024, dapu047, dapu055) and another three had E value higher than 0.01 (dapu046, dapu048, dapu132), which was treated as insignificant. Despite the fact that OpMNPV genome was annotated in the manner similar to AcMNPV, we chose to designate polh (gene encoding for polyhedrin) as first ORF in clockwise orientation, as it is adopted in recent full baculovirus genomes reports. According to this criterion, there is 76 ORFs in forward orientation and 85 in reverse orientation in DapuNPV genome. The ratio of forward to reverse located genes is almost the same in OpMNPV (72:80) and distinct from CfMNPV (73:73) and HycuNPV (Hyphantria cunea nucleopolyhedrovirus) (69:79). 


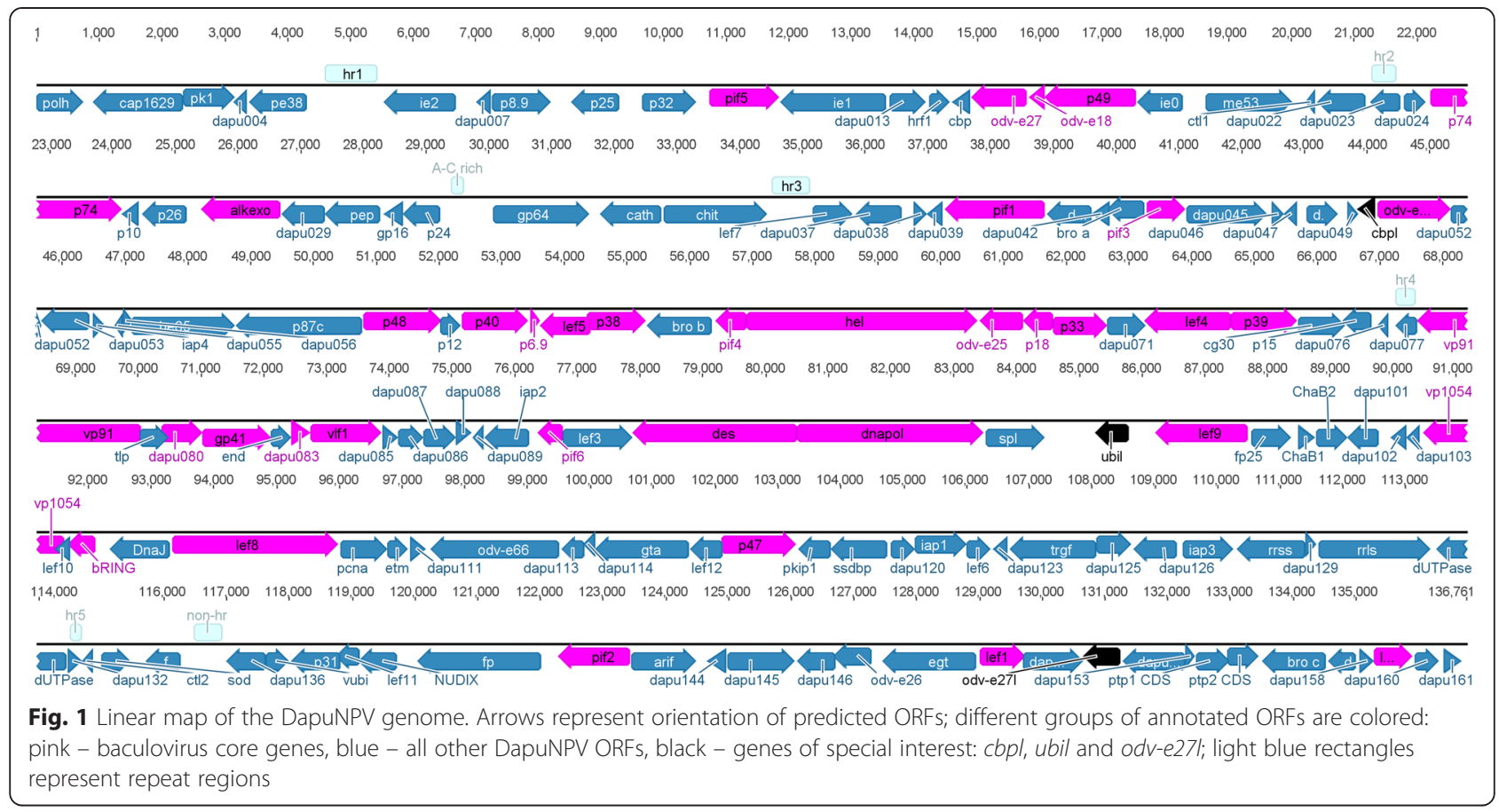

During NGS coverage analysis (i.e. how many single reads can be mapped to a corresponding location in the genome, which allows for the detection of possible recombinant viruses in a population) only a small narrowing can be observed in intergenic regions. The most significant one appears in $A-C$ rich region because of high di-nucleotide sequence composition. To confirm correct de novo assembly, the standard Sanger's sequencing was performed for this region. We detected one site of Single Nucleotide Polymorphism (SNP) that is located at the position 542 from beginning of $p 32$ gene. This $\mathrm{G}$ to $\mathrm{A}$ transition change translated amino acid from Arginine to Glutamine.

Recently discovered in Alphabaculovirus genus, a conserved, 156 bp long, non-protein-coding genomic element $(\mathrm{CNE})$, that is presumed to be responsible for virus replication in transfected insect cell cultures, is present also in the DapuNPV genome [30]. The CNE is located from $6,994 \mathrm{bp}$ to $7,149 \mathrm{bp}$ and partially overlaps with dapu007 ORF. This non-coding region shows the highest sequence identity (98.1\%) and similar sequence composition (AT content $60.9 \%$ ) with the corresponding one of OpMNPV.

Gene-parity plot analysis of DapuNPV against representatives from Alphabaculovirus Ia - AcMNPV (Autographa californica MNPV), Alphabaculovirus Ib - OpMNPV, Alphabaculovirus II - LyxyMNPV (Lymantria xylina MNPV), Betabaculovirus - CpGV (Cydia pomonella granulovirus), Gammabaculovirus - NeseNPV (Neodiprion sertifer NPV) and Deltabaculovirus - CuniNPV is shown in Fig. 2. Graphical interpretation of homologous blocks in viral genomes from group Ib is presented in Fig. 3.
Types of recombination such as inversions and dislocations were detected between DapuNPV ORFs: pe35-pif5 (for Choristoneura spp. NPVs, AgNPV (Anticarsia gemmatalis NPV) and EppoNPV (Epiphyas postvittana NPV), me54-p74 (for AnpeMNPV -Antheraea pernyi NPV-), PhcyNPV (Philosamia cynthia ricini NPV) and F-protein-dapu152 (for AgNPV, CfDEFMNPV (Choristoneura fumiferana defective MNPV)). The gene encoding superoxide dismutase (sod) was also inversed in AgNPV, CfDEFMNPV, PhcyNPV, AnpeMNPV and HycuNPV genomes.

\section{Phylogenetic relations to other baculoviruses}

According to its gene content, including gp64 and F-protein, DapuNPV is classified as a typical representative of the Alphabaculovirus group Ib [31]. To confirm this classification, phylogenetic Maximum Likelihood tree presented on Fig. 4 was generated using the alignments of each of the 37 single core genes concatenated into one MAFFT alignment (multiple sequence alignment based on fast Fourier transform). All 69 baculovirus genomes available in NCBI database until December 2014 and DapuNPV from this report were used (Additional file 2: Table S2). The nearest location of DapuNPV to OpMNPV on the phylogenetic tree is an additional confirmation of coevolution events between viruses and their hosts [9]. Both viruses were isolated from infected Lymantriidae caterpillars. To affirm this relationship, we conducted evolutionary analyses by calculating relative divergence times for all fully sequenced baculoviruses group Ib using nucleotide sites within the scope of collinear genes. The "RelTime" method 

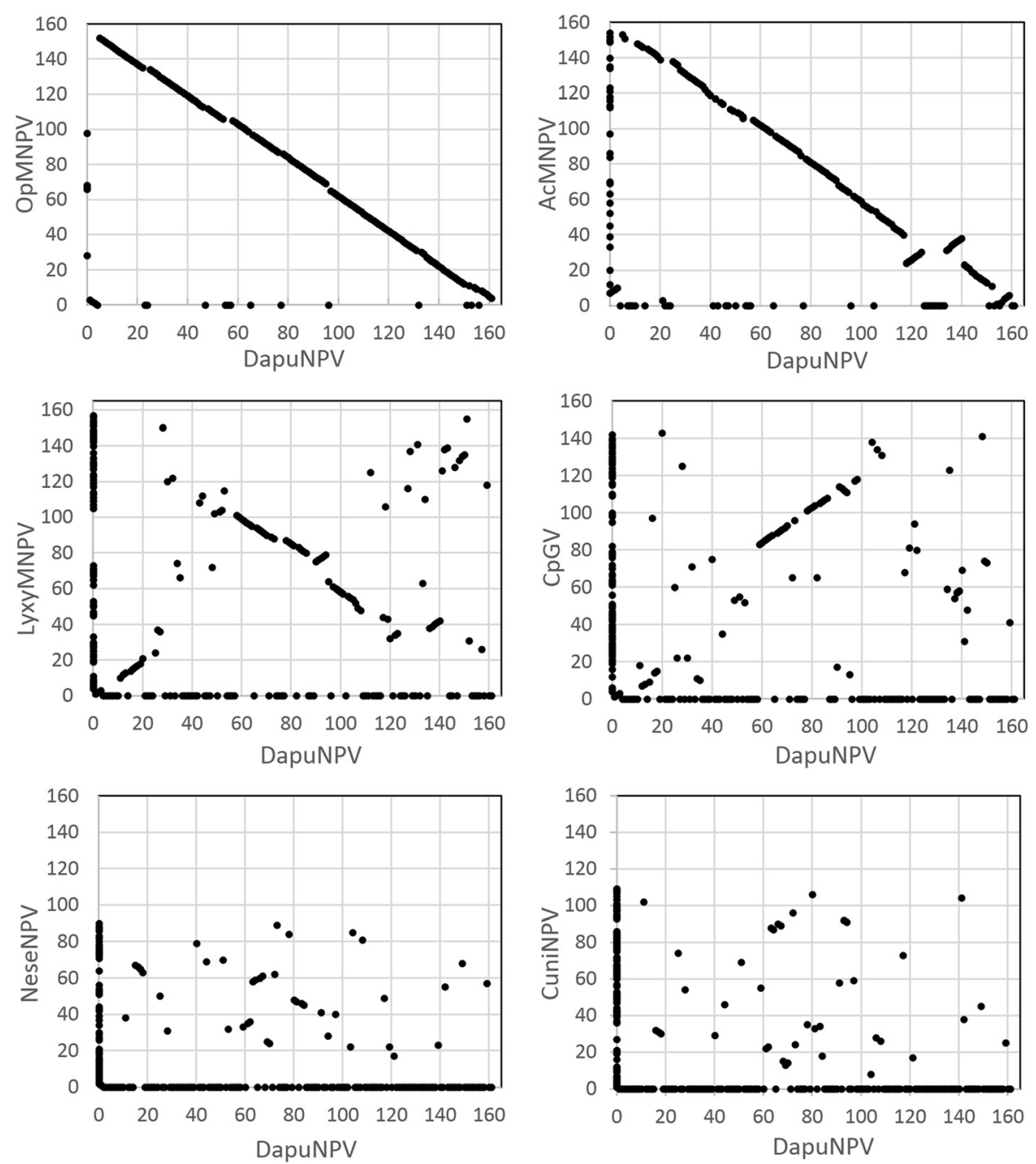

Fig. 2 Gene-parity plot analysis. Gene-parity plots of DapuNPV with OpMNPV, AcMNPV, LyxyNPV, CpGV, NeseNPV and CuniNPV based on ORF order where polh gene is considered as a first gene

used for creating tree presented in Fig. 5 indicates that possible divergence of ancestor baculovirus to DapuNPV and OpMNPV might have happened in the recent past compared to the first divergence in the clade. The method used for this deduction relies on the previous inferred molecular evolution and does not need any calibration events (e.g. absolute dating based on fossils). In a time span analogous for the divergence of DapuNPV and OpMNPV, two other pairs of closely related baculoviruses (AnpeMNPV and PhcyNPV, CfMNPV and ChocNPV) underwent similar evolutionary episode. The concurrence of these events may indicate occurrence of a particular timing when baculoviruses underwent their adaptation to hosts.

\section{Repetitive genomic regions}

Homologous repeats (hrs) are characteristic for almost all baculoviruses sequenced to date and consist of direct repeats, imperfect palindromes and high AT content. Within one viral genome they show homology, but it is hard to find similarities between different baculoviruses, except in those closely related. Hrs have been considered as origins of DNA replication in NPVs and GVs and transcriptional enhancers of early genes in NPVs (reviewed in [32, 33]). Additionally, non-homologous region (non-hr) origins of replication have been found in some NPVs [34].

The genome of DapuNPV has three types of repeated nucleotide sequences (Table 1): five homologous regions (from $h r 1$ to $h r 5$ ), one non-homologous region and one Adenine-Cytosine rich region $(A-C$ rich $)$. They all have highly similar equivalents in OpMNPV genome. The sequence and location of homologous regions are often conserved between related baculoviruses, although their lengths and copy numbers can vary from species to 


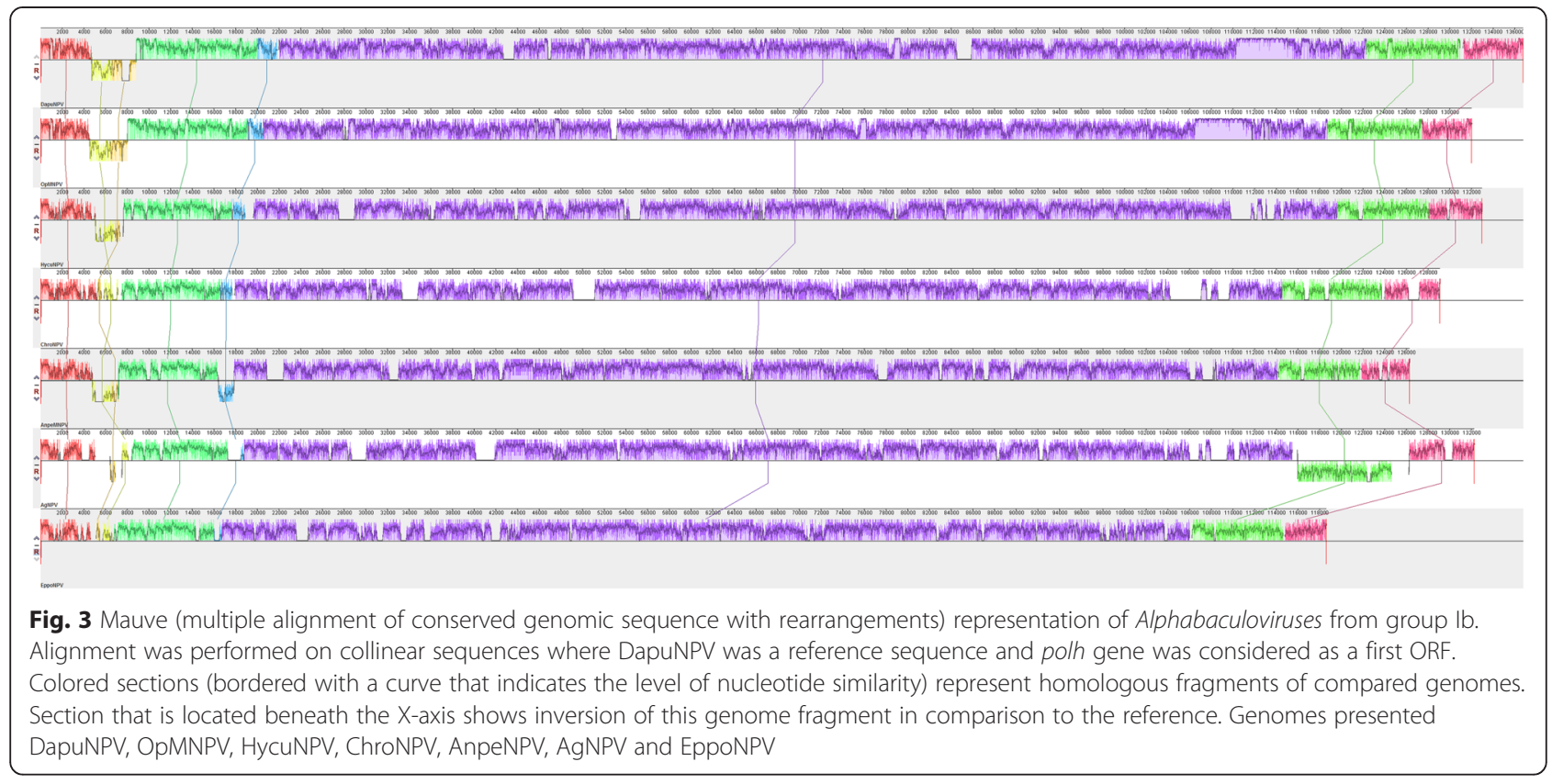

species. Every repeated element in DapuNPV hrs is composed of $30 \mathrm{bp}$ imperfect palindrome core sequence flanked by regions which are also highly conserved. Figure 6 shows multiple alignment of strict repeated elements consensus from each $h r$.

Surprisingly, DapuNPV hrs share higher level of sequence and localization similarity with HycuNPV than with Choristoneura spp. which is opposite to the genetic distance based on inferred evolutionary history of collinear genomes fragments (Fig. 5). Non-homologous repeated region occurs only in DapuNPV and OpMNPV, but some other Alphabaculoviruses group Ib can have homologous repeats in the corresponding sites of genomes (ChroNPV, ChocNPV, CfMNPV and EppoNPV). Another repeated element that is found only in DapuNPV and OpMNPV is an $A-C$ rich region. In DapuNPV it has $222 \mathrm{bp}$, it is around four times shorter than in OpMNPV baculovirus.

One of the characteristic features of the genomic sequence that flanks $h r$ regions is a high level of rearrangements (inversions, dislocations, deletions and insertions). These genome variations occur even between closely related baculovirus species. For example, conotoxins-like $(c t l)$ proteins are found in approximately one third of baculoviruses sequenced to date and some of them possess two genes of different lineages - ctl-1 and $c t l-2$. Conotoxins are a big family of small disulphide-bonded peptides, ion channel antagonists firstly isolated from marine cone snail venom. They are classified based on their disulphide pattern and biological features [35]. In baculoviruses $c t l$ is transcribed as a late gene and its product is a small secretory peptide not involved in viral infection in vivo or in vitro [36]. Multilocus presence of $c t l-1$ and $c t l-2$ occurs frequently in all Alphabaculovirus group Ib. In DapuNPV $c t l-2$ is located after $h r 5$ in the counter-clock orientation. Its homologue gene is inversed in HycuNPV, whilst entirely deleted in ChocNPV and AnpeMNPV.

\section{Two chitin binding protein families}

Chitin binding protein (ac145) is recognized in all groups of baculoviruses except for Deltabaculoviruses. It is considered as a possible pif gene (per os infectivity factor) that plays a significant role during early stages of larvae infection, as its deletion leads to a decrease in pathogenicity [37]. Sequencing of DapuNPV identified two ORFs, $c b p$ (ac145) and $c b p l$ (chitin binding protein like), as homologues of $a c 145$. Protein encoded by $c b p l$ gene (homologues were previously found in OpMNPV, AgNPV, CfDEFMNPV and AnpeMNPV, but not in other Alphabaculoviruses from group I) is composed of a signal peptide with a region similar to arthropod chitin binding peritrophin-A domain. Proteins with this domain are members of type I peritrophic membrane (PM) proteins, and by binding chitin they form a protective coating of the larvae midgut [38, 39]. Surprisingly, HMMER search showed that DapuNPV and OpMNPV $c b p l$ genes show higher level of similarity to Alphabaculoviruses from group II - LdMNPV and LyxyMNPV than to other, closely related baculoviruses. Unrooted ML tree (Fig. 7) confirmed that baculoviruses infecting insects from different species of Lymantriidae, possess $c b p l$ genes that are more similar to each other than to $c b p$ 


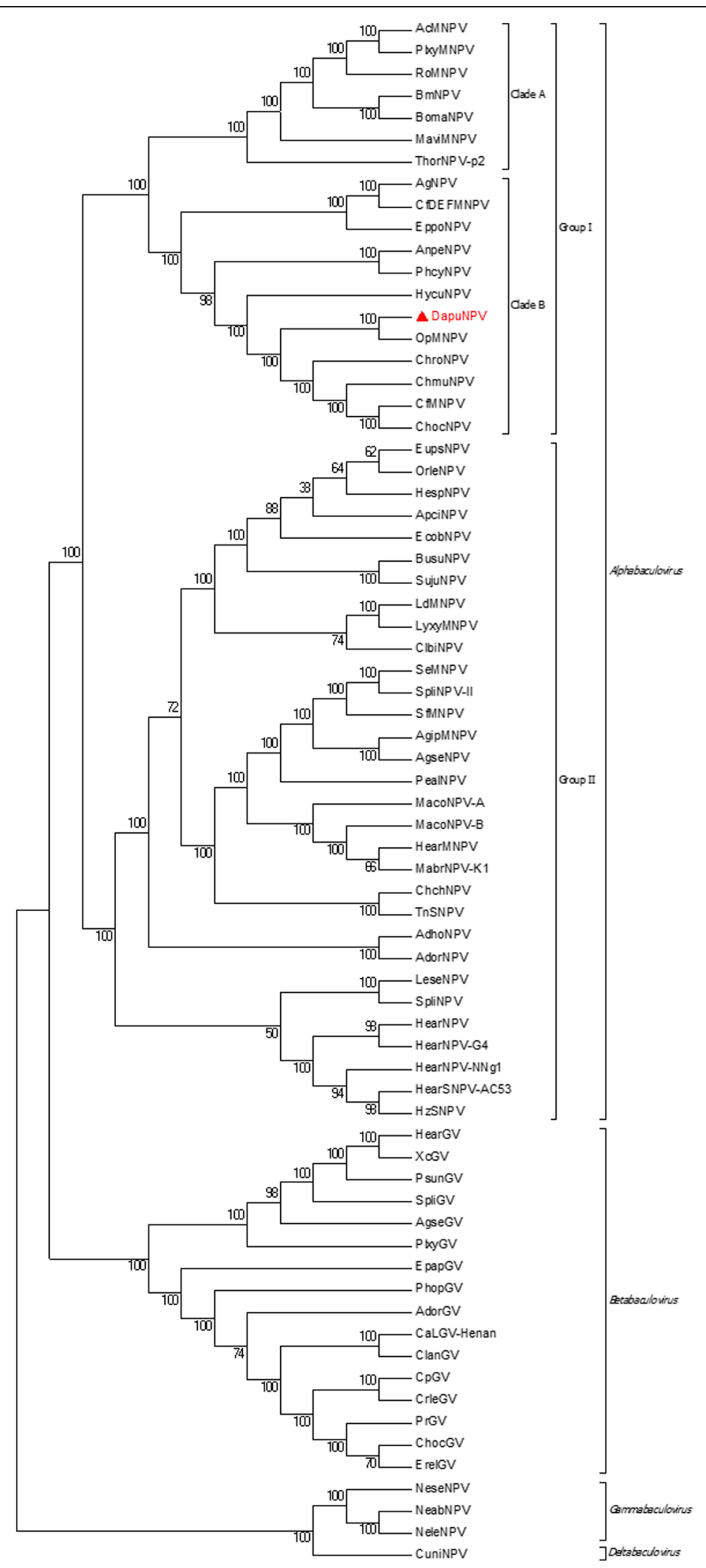

Fig. 4 Maximum Likelihood molecular phylogenetic analysis of 70 baculoviruses. Amino acid sequences of 37 core genes were analysed. The position of DapuNPV (labeled with red triangle) was shown clustering with OpMNPV in Alphabaculovirus group Ib 


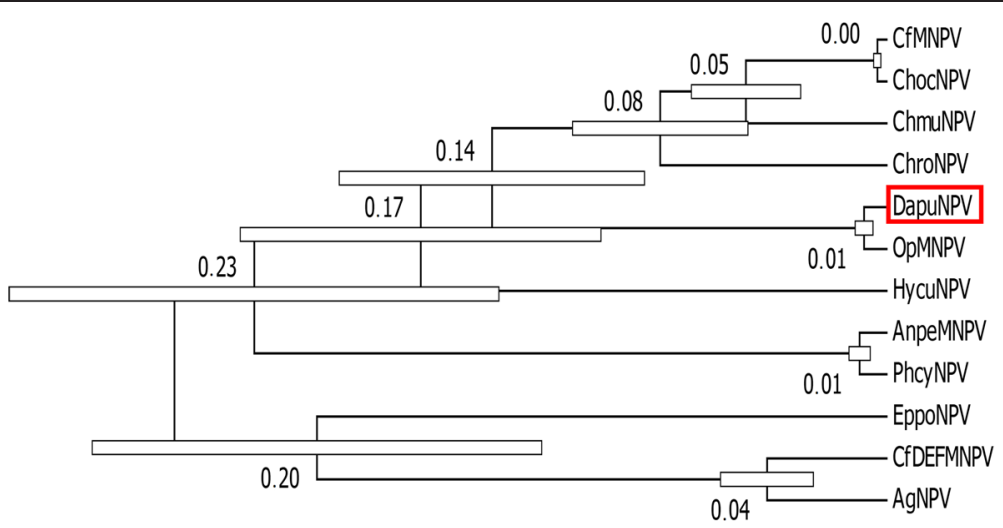

Fig. 5 Time tree molecular phylogenetic analysis of Alphabaculovirus group lb. Collinear homologue nucleotide regions of baculoviruses were analysed for their possible evolution history. The approximate relative time of divergence between two viruses is visualized by the wide bar on tree node. DapuNPV is highlighted by a red rectangle

genes even of the same species. This indicates that despite their structural similarities, $c b p$ and $c b p l$ do not arise from single gene duplication, but rather by horizontal transfer. In addition, our hypothesis on the origin of these proteins is supported by high bootstrap replicates. Probably, $c b p$ and $c b p l$ have the same function during viral life cycle. This would suggest that an evolutionary event (horizontal gene transfer) that occurred in the past, was fixed in those baculoviruses that can benefit from an additional factor able to disturb chitinprotein larvae peritrophic membrane rather than from replicon enlargement. Phylogenetic relationship of $c b p$ presented on the same tree is consistent with general baculovirus classification (Fig. 7).

\section{DapuNPV and OpMNPV genomic diversity}

We identified a nucleotide sequence that is $97.6 \%$ identical to ORF dapu004 in OpMNPV, but is has not been annotated there. This gene with late promoter motif and intrinsically unstructured/disordered protein fragment has its homologue in other Alphabaculoviruses Ib (chro004). Based on its predicted structure, this protein, if transcribed, could potentially contribute to cell-cycle regulation, signal transduction or transcription [40, 41].
Highly basic p8.9 protein was described as an unique 228 bp long ORF in OpMNPV. In DapuNPV genome p8.9 ORF is built of $942 \mathrm{bp}$ due to the large insertion in its central region (Additional file 3: Figure S1). Search against Pfam database do not yield any results, though the confirmed translation in OpMNPV supports the hypothesis that the homologue of $\mathrm{p} 8.9$ protein plays a role in DapuNPV life cycle. The predicted molecular mass for this DapuNPV protein is approximately $36 \mathrm{kDa}$. The composition of four basic amino acids specific for OpMNPV p8.9 is about $30.2 \%$, while for DapuNPV it is equal $25 \%[42,43]$.

A universal trait of many eukaryotic dsDNA viruses is the presence of multigene families (MGFs) containing related repeated open reading frames (ORFs) scattered within the genome. The Baculoviridae family also contains their own group of such genes called bro genes (baculovirus repeated ORFs), that differ in number and length from one virus to another [44]. These sequences are present in species from all genera, except in Gammabaculovirus, in up to 16 (LdMNPV) copies per genome [45]. However, they are absent in RoMNPV (Rachiplusia ou MNPV) [46] and PlxyGV (Plutella xylostella GV) [47]. DapuNPV genome has three bro ORFs ( $a, b$ and c). Bro a homologues can be found in all

Table 1 Repeated regions of the DapuNPV

\begin{tabular}{|c|c|c|c|c|}
\hline Repeat region name & Strict consensus nucleotide sequence & Repeated element length & Repeated element copies $^{\mathrm{a}}$ & Location ORF \\
\hline$\overline{h r l,}$ & \multirow{5}{*}{$\begin{array}{l}\text { GCACCGCTAAAAATAGCACDCGCCTTTCGAGAG } \\
\text { CGATCGCACCCGAAAAGCAGGGTCGTCGCTGAC }\end{array}$} & 66 & 13 & pe38-ie2 \\
\hline$h r 2$ & & 66 & 6 & dapu023 \\
\hline$h r 3$, & & 66 & 10 & chit - lef7 \\
\hline hr4, & & 66 & 5 & dapu077 \\
\hline hr5 & & 66 & 4 & dapu132 \\
\hline non-hr & AAARTRATGAYTCATGYTADAKCAAGGTY & 29 & 16 & fgf - dapu136 \\
\hline A-C rich & AMACAMACAMAC & 12 & 16 & p24 - gp64 \\
\hline
\end{tabular}

aevery truncated element was counted as one 


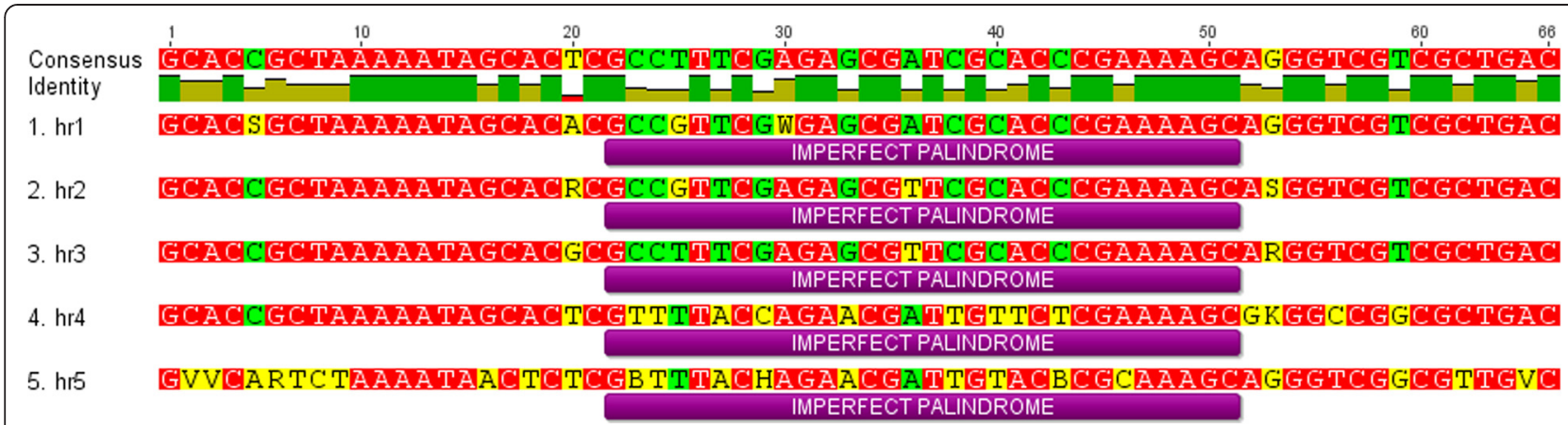

Fig. 6 Multiple alignment of all DapuNPV hr regions. Bar below sequences highlights palindrome core region (MAFT multiple alignment with default settings, gaps ignored, visualization in Geneious R7)

Alphabaculoviruses Ib; bro $b$ as a functional homologue is present in HycuNPV, AnpeMNPV and PhcyNPV, while bro $c$ can be recognized in HycuNPV, CfDEFMNPV, AgNPV. In ChocNPV and CfMNPV the latter two bro genes are shorter and dislocated. OpMNPV genome encodes a shorter homologue than DapuNPV bro a gene. Variations in numbers, locations and content of baculovirus bro genes between closely related species are their well-known characteristic [44].

DapuNPV nucleotide sequences corresponding to dapu023 and dapu024 are only partly present in OpMNPV genome in $h r 5$ region. Because in OpMNPV this fragment is much shorter than in DapuNPV it does not form any ORF. DapuNPV consecutive ORFs dapu046, dapu047 and dapu048 have no homologues in any dsDNA viruses. An early promoter motif is placed upstream the first gene, whilst the remaining two genes encode transmembrane domain containing protein and a single prokaryotic RING finger family four domain containing protein respectively, which may indicate a bacterial origin of this fragment of the genome. In the same region of OpMNPV genome (between op111op114 that corresponds to dapu045-dapu049), two conserved ORFs are present but are not found in DapuNPV.

Two ORFs, not previously described, with early promoter motifs (dapu55 and dapu56) are located after DapuNPV iap4 gene. The nucleotide sequence corresponding to this two genes cannot be found in OpMNPV genome. DapuNPV iap4 is almost half shorter than OpMNPV iap 4 because of a 88 bp deletion and a frame

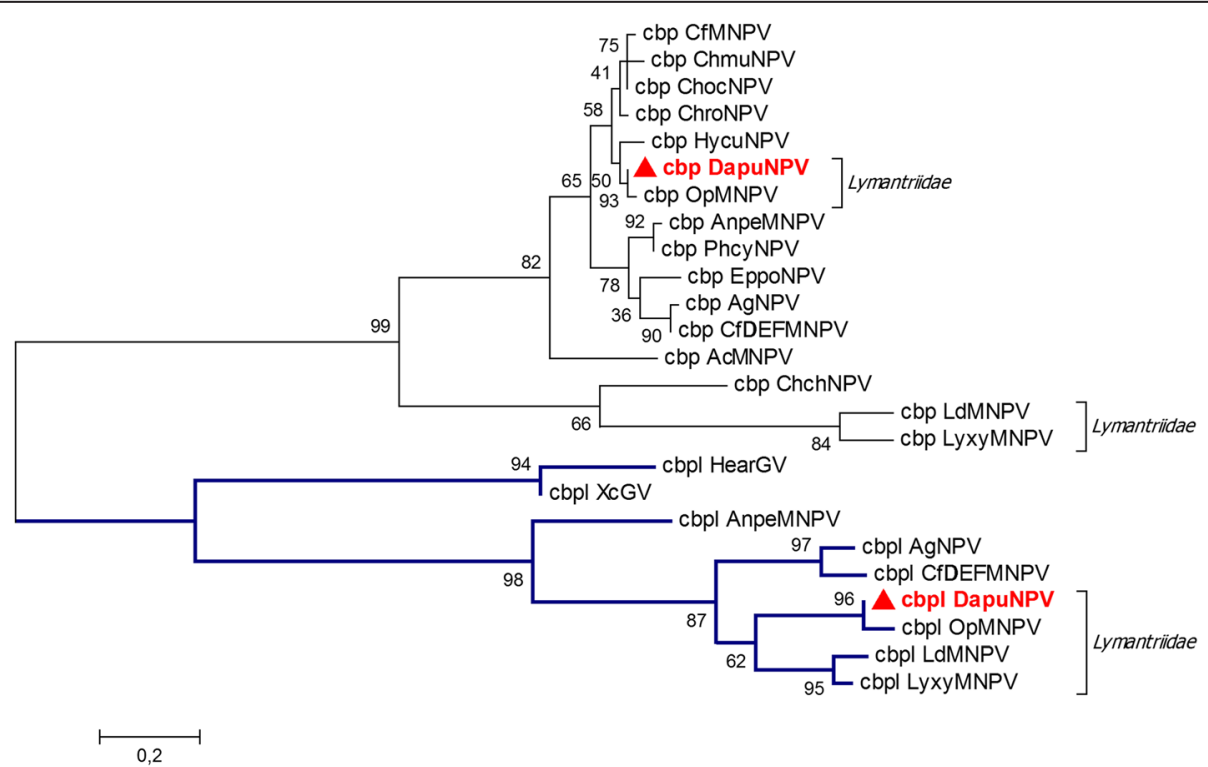

Fig. 7 Maximum Likelihood molecular phylogenetic analysis of two chitin binding baculoviruses proteins. Two (cbp and cbpl) similar genes show different pattern of clustering. Cbp/ highlighted by blue tree branch groups more host-specific species than cbp. The positions of DapuNPV was labeled with a red triangle 
shift. Subsequent ORF he65 of DapuNPV shows $73 \%$ nucleotide identity to he65 from Alphabaculovirus Ib AnpeNPV where in OpMNPV only 205 bp of 3' of full 1650 bp DapuNPV gene is present. This OpMNPV short region does not code putative gene. He65 protein is one of the representatives of RNA ligases family and is prevalent in Archea, Bacteria and Eukarya. It is an early transcribed gene involved in RNA replication, transcription and modification, as well as in G-actin localization in nucleus during AcMNPV-cells infection. It is considered as a nonessential protein for AcMNPV and BmNPV [48, 49]. Homologues of ac105 encoding he65 gene are found in 27 baculovirus genomes (sequenced to date; genes called he65 or annotated as similar to ac105). They are present in 22 members of Alphabaculovirus genus: in all seven from group Ia, five from Ib (among others ag101, cfDEF97 and dapu57), ten from group II (e.g. agip25, chch73, lese68) and five members of Betabaculoviruses (agse132, erel36, hear62, psun63, xc67). In almost half of these cases he65 gene is placed close (upstream or downstream) to late gene encoding structural vp80/p87 protein (NPVspecific protein).

Another ORF that shows INDELS (insertions-deletions) type variation between DapuNPV and OpMNPV is dapu071, where the deletion of 228 bp located in the middle of the gene does not change the reading frame.

The region in the sequence between DapuNPV $s p l$ (spheroidin-like) and lef9 genes is highly variable in Alphabaculoviruses Ib. For example in OpMNPV and ChroNPV there is a bro gene, absent in DapuNPV. This dissimilarity is $650 \mathrm{bp}$ in length in OpMNPV and 1394 bp in DapuNPV, where 534 bp encode ubiquitin like protein $(u b i l)$; its gene is controlled by an early promoter and does not have a homologue in any baculoviruses (the closest search hit during HMMER was a Polyubiquitin-C protein from Mus musculus; E value $1.2 \mathrm{e}-22$ ). Additionally ubil gene locus (it does not overlap with other ORF) and protein size (177 amino acids) confirm of its existence. Ubiquitin is highly conserved and abundant in all eukaryotes, which indicates its crucial role in cell cycle. The main function in a cell is to direct proteins to degradation pathway but it also takes part in stress response, ribosome biogenesis, and cell differentiation [50]. DapuNPV genome encodes also another ubiquitin gene (vubi - viral ubiquitin) whose homologues have been found in wide range of viruses [51]. Viral ubiquitin proteins are characteristic for all lepidopteran baculovirus species, that make them core genes for Alpha- and Betabaculovirus, none of them is present in dipteran- or hymenopteran-specific members of Baculoviridae family [5]. DapuNPV ubiquitin like (ubil) seems not to be related to viral ubiquitin (vubi) gene conserved in baculoviruses as it has only $30 \%$ nucleotide identity and $17 \%$ amino acid identity.

\section{DapuNPV is a first Alphabaculovirus group I with two copies of odv-e27 gene}

Odv-e27 is a structural protein. Although it was named odv-ec27 (occlusion derived virus envelope and capsid [52]) it is present in both phenotypic forms of baculoviruses like ODV and BV [53]. It is also presumed to be essential for budded virus production [54]. Odv-ec27 was also reported to act as a viral cyclin that participates in cell cycle regulation during infection [55]. Homologues of gene $o d v-e c 27$ (ac144) belong to core genes, so it is prevalent in all sequenced to date baculoviruses [5] in one copy, except for single Alphabaculovirus group II - LyxyMNPV where two genes have been identified [56]. The DapuNPV is a second baculovirus with additional copy of $o d v-e 27$ gene. While DapuNPV 194 amino acids (aa) protein is similar to smaller copy of LyxyMNPV protein odv-e27 (188 aa), it shares only $25.1 \%$ BLSM62 pairwise positivity (23\% amino acid identity). Odv-e27 proteins that are encoded by baculovirus core genes are more similar to each other than to DapuNPV odv-e271 (odv-e27 like protein) or shorter LyxyMNPV odv-e27 protein. Inferred evolutionary history for 70 core gene odv-e27 and two short versions form DapuNPV and LyxyMNPV revealed that shorter versions cluster together distantly from core genes (data not shown). The duplication of $o d v-e 27$ genes and close phylogenetic relationship of $c b p l$ homologues reveals a surprising connection between evolutionary distinct Alphabaculoviruses that infect insects from the Lymantriidae family.

\section{Protein tyrosine phosphatase}

In general, parasites are known to change their hosts behavior during infection. A great diversity of behavioral changes may occur such as in feeding, mating, odor response and activity. In most cases direct molecular causes have not been yet described [57]. However, in baculoviruses, egt gene has been noted as responsible for 'tree top disease', i.e. it induces climbing behavior in gypsy moth Lymantria dispar L. caterpillars during late stages of infection, in order to spread progeny virus on a wider range of healthy larvae [58]. Another gene $p t p$ encoding protein tyrosine phosphatase has also been shown to participate in behavioral changes of the host Bombyx mori L. by strongly enhancing locomotory response to infection in caterpillars, which are normally almost immotile $[59,60]$. The viral ptp is a component of the virion, consists of $\mathrm{HC}$ motif, where cysteine residues are necessary for its function as an active phosphatase [61]. Protein tyrosine phosphatase gene is present in all lepidopteran NPVs in group I. Phylogenetic analysis implies that egt as well as ptp genes appear to have a lepidopteran origin [62]. During the annotation process of the assembled DapuNPV genome, all different tools used predicted three genes that are located one behind 
the other. We named them dapu123, ptp1 and ptp2. Comparative genomic analyses between DapuNPV and Alphabaculoviruses show that ptp genes are highly conserved in genomic sequence, but in many species $p t p 2$ is not present (AcMNPV, HycuNPV, EppoNPV). ORF dapu123 was not predicted in any baculovirus, mainly due to a mutation that changes a reading frame which introduces STOP codon earlier to predicted transcript (Choristoneura spp. viruses). A genome fragment responsible for this three ORFs is in $98 \%$ similar to OpMNPV. However, in OpMNPV baculovirus, $p t p 1$ was annotated as a longer gene that has its start inside DapuNPV dapu123 gene. This ORF enlargement in OpMNPV is not supported by genomic sequence from any analyzed Alphabaculovirus group I. Since comparative genome data is consistent with the data obtained from the bioinformatic tools that we used, we decided to distinguish ORFs: dapu123 and ptp1 (wherein the second one starts from a codon located 129 bp downstream in comparison to its OpMNPV homologue).

\section{Conclusions}

DapuNPV baculovirus is closely related to OpMNPV but possesses a few distinctive features. The most prominent ones are genes similar to $u b i$ (called ubil) and $o d v-e 27$ (called odv-e27l). The first gene does not have any homologue in baculoviruses while the second one can be found only in one member of Alphabaculovirus group II - LyxyMNPV. This connection between members of evolutionary distinct groups of baculoviruses which infect the same hosts from the Lymantriidae is also supported by the shared homologue cbpl gene. DapuNPV and OpMNPV have $91.1 \%$ of nucleotide uniformity though there are some differences in gene content (e.g. he65). Study on phylogenetic relationship between baculoviruses was prepared based on alignment containing amino acid core gene sequences from 70 members of Baculoviridae family that were manually picked and confirmed.

\section{Nucleotide sequence accession number}

The DapuNPV genome sequence was submitted to GenBank under accession number KP747440.

\section{Availability of supporting data}

The complete DapuNPV genome sequence has been submitted to GenBank (accession number KP747440). All supporting data are included as additional files.

\section{Methods}

\section{Virus purification and DNA extraction}

Late instars of pale tussock moth caterpillars infected by baculovirus were collected in 2010. The presence of polyhedra was confirmed with light microscope. Larvae were mechanically homogenized in deionized distilled water $\left(\mathrm{ddH}_{2} \mathrm{O}\right)$. The homogenate was filtered through cheesecloth to remove pieces of cuticle. Afterwards the filtrate was centrifuged at $5000 \times \mathrm{g}$ for $10 \mathrm{~min}$ in room temperature (RT). The supernatant was discarded, the pellet consisting of polyhedra was resuspended in $0.5 \%$ SDS and centrifuged at $5000 \times \mathrm{g}$ for $10 \mathrm{~min}$ at RT. Then again the pellet was resuspended in $0.5 \mathrm{M} \mathrm{NaCl}$ and centrifuged as before. The pellet was resuspended in $\mathrm{ddH}_{2} \mathrm{O}$ and loaded onto a linear $40-65 \%$ sucrose gradient and ultracentrifuged at $96,000 \times \mathrm{g}$ for $3 \mathrm{~h}$ at RT. The collected milky polyhedral band was diluted in $\mathrm{ddH}_{2} \mathrm{O}$ and pelleted by centrifugation at $10,000 \times \mathrm{g}$ for $10 \mathrm{~min}$ at $4{ }^{\circ} \mathrm{C}$ (this step was repeated twice). After final resuspension polyhedra were dissolved in an alkaline solution (0.1 $\left.\mathrm{M} \mathrm{Na}_{2} \mathrm{CO}_{3}, \mathrm{pH} 10.0\right)$ for $30 \mathrm{~min}$. Equal volume of Tris $\mathrm{pH} 6.4$ buffer was used for neutralization followed by DNA extraction by MagAttract HMW DNA Kit (Qiagen) according to manufacturer's protocol. DNA prior to sequencing procedure was diluted in nuclease-free water.

\section{Genome sequencing and assembly}

DNA sequencing was done at the Medical University of Gdansk in Poland, using Miseq (Illumina). For genomic library preparation Nextera XT DNA sample prep kit (Illumina) was used. During machine run, paired reads of the target size $2 \times 300$ were generated. After trim procedure, 294,902 reads with at least Q30: $96.8 \%$ were used to produce single circular contig by de novo assembling using Geneious 7 (Biomatters http://www.geneious.com/). The mean coverage was 156.7 with minimum 67 and maximum 904. Regions with repeated sequences were confirmed by PCR amplification and Sanger sequencing.

\section{Genome annotation and phylogeny}

Establishment of full nucleotide sequence of DapuNPV was followed by open reading frames (ORFs) prediction. ORFs were identified only when they had been indicated by two or more following tools that use different algorithms (with exceptions when published data indicates otherwise): Glimmer3 (gene model pre-computed on OpMNPV genome) [63], GeneMarkS (parameter: Intron less eukaryotic-virus) [64] (http://linux1.softberry.com/ berry.phtml?topic $=$ virus 0 \&group $=$ programs $\&$ subgroup $=$ gfindv) and tcode EMBOSS 6.5.7 [65]. Putative ORFs were then annotated by search of their translated amino acid sequence in protein database using HMMER web server (phmmer, NR large collection, scoring matrix BLOSUM62 and BLOSUM45) [66]. The scans for Pfam domains, signal peptides, disordered, transmembrane and coiled-coil regions were integrated into HMMER search and their results were presented for all previously unknown putative ORFs [40, 41, 67, 68]. For repeated 
sequences the Tandem Repeats Finder and PHOBOS software were used $[69,70]$. Promoter motifs were searched in the $150 \mathrm{bp}$ upstream region from first nucleotide of any predicted ORF. Early promoter was recognized when TATA box was present and late when DTAAG box could be found. Amino acid sequence corresponding to predicted genes was extracted and used for multiple alignment with proteins belonging to other baculoviruses. MAFFT (Multiple Alignment using Fast Fourier Transform) software with automatic algorithm selection was used. Files containing aligned sequences were exported to MEGA6 (Molecular Evolutionary Genetics Analysis) software for phylogenetic analysis $[71,72]$. In order to be certain of the choice of the correct substitution model and its parameters for inferred evolutionary history, two tests that are built in MEGA6 software were performed: first based on Bayesian Information Criterion and second corrected Akaike Information Criterion. The phylogeny was established by using the Maximum Likelihood method based on the LG + G + I + F matrix model [73]. The percentage of 1000 bootstrap replicates in which the associated baculoviruses clustered together is shown next to the branches. For tree showing all sequenced genomes of baculoviruses only topology is presented. The tree showing phylogeny of $c b p$ is drawn to scale, with branch lengths measured in the number of substitutions per site. The time tree shown for coding collinear genome fragments of Alphabaculoviruses group Ib (Fig. 5) was generated using the RelTime method [74]. Collinear genomic sequences from different baculoviruses were aligned using Mauve algorithm implemented in Geneious 7 software [75]. This method allows to recognize homologous regions of multiple sequences and align them to each other.

\section{Additional files}

Additional file 1: Table S1. Predicted ORFs and repeat regions in the genome of DapuNPV. This file lists the ORFs predicted (with its direction and promoter sequences) in the genome of DapuNPV and their homologues in 15 other completely sequenced baculoviruses. (XLSX $31 \mathrm{~kb}$ )

Additional file 2: Table S2. List of sequenced to date baculoviruses. This file lists all baculoviruses sequenced to date, with their accession number, genome length and source of the sequence. (DOCX $31 \mathrm{~kb}$ )

Additional file 3: Figure S1. Alignment of OpMNPV p8.9 ORF and its homologue in DapuNPV genome. Large insertion after nucleotide 201 in DapuNPV gene does not change the reading frame, although it decreases total basicity of translated protein which is a specific feature of p8.9 protein from OpMNPV (MAFT multiple alignment with default settings, visualization in Geneious R7). (PNG 80 kb)

\section{Competing interests}

The authors declare that they have no competing interests.

\section{Authors' contributions}

$M K, I S, B S$ and $L R$ proposed and designed the experiments. MK and BW performed the experiments, MK and LR analyzed the bioinformatics data and LR prepared phylogenetic trees. MK, IS, BS, and LR wrote the paper. All authors approved the final manuscript.

\section{Acknowledgements}

This work was supported by financial grant UMO-2011/03/N/NZ9/02215 from National Science Centre (Poland). Open access publication cost supported by the European Commission from the FP7 project MOBI4Health.

\section{Author details}

${ }^{1}$ Department of Recombinant Vaccines, Intercollegiate Faculty of Biotechnology University of Gdansk and Medical University of Gdansk, 80-822 Gdansk, Kladki Str. 24, Poland. ${ }^{2}$ Forest Research Institute, Department of Forest Protection, 05-090RaszynBraci Lesnej Str. 3, Sekocin Stary, Poland. ${ }^{3}$ Department of Biology and Genetics, Medical University of Gdansk, 80-211 Gdansk, Debinki Str. 1, Poland.

Received: 6 February 2015 Accepted: 29 September 2015

Published online: 08 October 2015

\section{References}

1. Blissard GW, Rohrmann GF. Baculovirus diversity and molecular biology. Annu Rev Entomol. 1990;35:127-55.

2. Lange $\mathrm{M}$, Wang $\mathrm{H}$, Zhihong $\mathrm{H}$, Jehle JA. Towards a molecular identification and classification system of lepidopteran-specific baculoviruses. Virology. 2004;325(1):36-47.

3. Lauzon HA, Lucarotti CJ, Krell PJ, Feng Q, Retnakaran A, Arif BM. Sequence and organization of the Neodiprion lecontei nucleopolyhedrovirus genome. J Virol. 2004;78(13):7023-35.

4. Hayakawa T, Ko R, Okano K, Seong SI, Goto C, Maeda S. Sequence analysis of the Xestia c-nigrum granulovirus genome. Virology. 1999;262(2):277-97.

5. Garavaglia MJ, Miele SA, Iserte JA, Belaich MN, Ghiringhelli PD. The ac53, ac78, ac101, and ac103 genes are newly discovered core genes in the family Baculoviridae. J Virol. 2012;86(22):12069-79.

6. Murphy FA, Fauquet CM, Bishop DHL, Ghabrial SA, Jarvis AW, Martelli GP, et al. Virus taxonomy - the classification and nomenclature of viruses: Sixth report of the international committee on taxonomy of viruses. New York: Springer Verlag; 1995.

7. Blissard G, Black B, Crook N, Keddie BA, Possee R, Rohrmann G, et al. Family baculoviridae. In: van Regenmoertel MHV, Fauquet CM, Bishop DHL, Carstens EB, Estes MK, Lemon SM, Maniloff J, Mayo MA, McGeoch DJ, Pringle $\mathrm{CR}$, Wickner RB, editors. Virus taxonomy — seventh report of the international committee on taxonomy of viruses. San Diego: Academic; 2000. p. 195-202.

8. Herniou EA, Olszewski JA, O'Reilly DR, Cory JS. Ancient coevolution of baculoviruses and their insect hosts. J Virol. 2004;78(7):3244-51.

9. Jehle JA, Lange $M$, Wang $H$, Hu Z, Wang Y, Hauschild R. Molecular identification and phylogenetic analysis of baculoviruses from Lepidoptera. Virology. 2006;346(1):180-93.

10. Miele SA, Garavaglia MJ, Belaich MN, Ghiringhelli PD. Baculovirus: molecular insights on their diversity and conservation. Int J Evol Biol. 2011;2011:379424.

11. Hefferon KL, Oomens AG, Monsma SA, Finnerty CM, Blissard GW. Host cell receptor binding by baculovirus GP64 and kinetics of virion entry. Virology. 1999;258(2):455-68.

12. Pearson MN, Groten C, Rohrmann GF. Identification of the Lymantria dispar nucleopolyhedrovirus envelope fusion protein provides evidence for a phylogenetic division of the Baculoviridae. J Virol. 2000;74(13):6126-31.

13. ljkel WF, Westenberg M, Goldbach RW, Blissard GW, Vlak JM, Zuidema D. A novel baculovirus envelope fusion protein with a proprotein convertase cleavage site. Virology. 2000;275(1):30-41.

14. Wang $M$, Wang J, Yin F, Tan Y, Deng F, Chen $X$, et al. Unraveling the entry mechanism of baculoviruses and its evolutionary implications. J Virol. 2014;88(4):2301-11.

15. Jiang $Y$, Deng F, Rayner S, Wang $H$, Hu Z. Evidence of a major role of GP64 in group I alphabaculovirus evolution. Virus Res. 2009;142(1-2):85-91.

16. Herniou EA, Arif BM, Becnel JJ, Blissard GW, Bonning BC, Harrison R, et al. Baculoviridae. In: King AMQ, Adams MJ, Carstens EB, Lefkowitz EJ, editors. Virus taxonomy: Ninth report of the international committee on taxonomy of viruses. New York: Elsevier Academic Press; 2011.

17. Novak V, Hrozinka F, Stary B. Atlas of insects harmful to forest trees, vol. 1. New York: Elsevier Scientific Publishing Company; 1976.

18. Kimoto T, Duthie-Holt M. Calliteara pudibunda (Linnaeus) In: Exotic Forest Insect Guidebook. Canadian Food Inspection Agency. 2006: p.6. 
19. Mazzoglio PJ, Paoletta M, Patetta A, Currado I. Calliteara pudibunda (Lepidoptera Lymantriidae) in Northwest Italy. Bulletin of Insectology. 2005;58(1):25-34.

20. Klimitzek D. Das Vorkommen des Buchenrotschwanzes (Dasychira pudibunda L.) in der Pfalz. Allgemeine Forstund Jagd-Zeitung. 1972:143(9):192-5.

21. Wellenstein G. Lymantriidae, traegspinner. In: Schwenke W, editor. Die Forstschaedlinge Europas. 3. Schmetterlinge. Berlin und Hamburg: Verlag P. Parey; 1978. p. 316-34.

22. Sylven E. Die Biologie des Buchenspinners Dasychira pudibunda L. Z Angew Entomol. 1944;30(1):119-42.

23. Heqvist KJ. Om bokspinnarens (Dasychira pudibunda L.) uppträdande i Halland år 1946. Svenska Skogsvårdsföreningens Tidskrift. 1949;4:219-27.

24. Nilsson I. The influence of Dasychira pudibunda (Lepidoptera) on plant nutrient transports and tree growth in a beech Fagus sylvatica forest in southern Sweden. Oikos. 1978;30:133-48.

25. Meullengracht-Madsen J, Nielsen PS: Mass occurrence of the larvae Dasychira pudibunda in southern Sjaelland, 2001 [online www.lepidoptera.dk/pudibund.htm]

26. Paramonov AJ. Zur Frage nach der forstwirtschaftlichen Bedeutung von Dasychira pudibunda L., Travaux du Musée Zoologique de l'Académie des Sciences d'Ukraine Kiev. 1935;14:81-9.

27. Instytut Badawczy Leśnictwa - analizy i raporty. Krótkoterminowa prognoza występowania ważniejszych szkodników i chorób infekcyjnych drzew leśnych w Polsce w 2014 roku. Sękocin Stary, Polska: Instytut Badawczy Leśnictwa; 2014.

28. Cory JS, Hails RS. The ecology and biosafety of baculoviruses. Curr Opin Biotechnol. 1997;8:323-27.

29. Krieg A, Langenbuch R. A polyhedral virus disease of Dasychira pudibunda L. (Lepidoptera, Lymantridae). Arch Gesamte Virusforsch. 1956;7(1):18-27.

30. Kikhno I. Identification of a conserved non-protein-coding genomic element that plays an essential role in Alphabaculovirus pathogenesis. PLoS One. 2014:9(4):e95322.

31. Herniou EA, Jehle JA. Baculovirus phylogeny and evolution. Curr Drug Targets. 2007;8(10):1043-50.

32. Berretta MF, Romanowski V. Baculovirus homologous regions (hrs): pleiotropic functional cis elements in viral genomes and insect and mammalian cells. Current Topics in Virology Research Trends. 2008;7:47-56.

33. Rohrmann G. Early events in infection: virus transcription. In: Baculovirus Molecular Biology, Third edition. Bethesda (MD): National Center for Biotechnology Information (US), 2013.

34. Ferrelli ML, Berretta MF, Belaich MN, Ghiringhelli D, Sciocco-Cap A, Romanowski V. The baculoviral genome. In. Viral Genomes - Molecular Structure, Diversity, Gene expression mechanisms and host-virus interactions. Edited by Maria Garcia, InTech Open, 2012. http://www.intechopen.com/ books/viral-genomes-molecular-structure-diversity-gene-expression mechanisms-and-host-virus-interactions/the-baculoviral-genome. ISBN 978-953-51-0098-0. DOI: 10.5772/32209.

35. Balaji RA, Ohtake A, Sato K, Gopalakrishnakone P, Kini RM, Seow KT, et al. lambda-conotoxins, a new family of conotoxins with unique disulfide pattern and protein folding. Isolation and characterization from the venom of Conus marmoreus. J Biol Chem. 2000;275(50):39516-22.

36. Eldridge $R$, Li Y, Miller LK. Characterization of a baculovirus gene encoding a small conotoxinlike polypeptide. J Virol. 1992;66(11):6563-71.

37. Lapointe R, Popham HJ, Straschil U, Goulding D, O'Reilly DR, Olszewski JA. Characterization of two Autographa californica nucleopolyhedrovirus proteins, Ac145 and Ac150, which affect oral infectivity in a host-dependent manner. J Virol. 2004;78(12):6439-48.

38. Guo W, Li G, Pang Y, Wang P. A novel chitin-binding protein identified from the peritrophic membrane of the cabbage looper, Trichoplusia ni. Insect Biochem Mol Biol. 2005;35(11):1224-34.

39. Zhong XW, Wang XH, Tan X, Xia QY, Xiang ZH, Zhao P. Identification and molecular characterization of a chitin deacetylase from Bombyx mori peritrophic membrane. Int J Mol Sci. 2014;15(2):1946-61.

40. Dosztanyi Z, Csizmok V, Tompa P, Simon I. The pairwise energy content estimated from amino acid composition discriminates between folded and intrinsically unstructured proteins. J Mol Biol. 2005;347(4):827-39.

41. Dosztanyi Z, Csizmok V, Tompa P, Simon I. IUPred: web server for the prediction of intrinsically unstructured regions of proteins based on estimated energy content. Bioinformatics. 2005:21(16):3433-4.

42. Ahrens CH, Russell RL, Funk CJ, Evans JT, Harwood SH, Rohrmann GF. The sequence of the Orgyia pseudotsugata multinucleocapsid nuclear polyhedrosis virus genome. Virology. 1997;229(2):381-99.
43. Russell RL, Rohrmann GF. Nucleotide sequence of the ubiquitin-39 K gene region from the Orgyia pseudotsugata multinucleocapsid nuclear polyhedrosis virus genome. J Gen Virol. 1993;74(Pt 6):1191-5.

44. Bideshi DK, Renault S, Stasiak K, Federici BA, Bigot Y. Phylogenetic analysis and possible function of bro-like genes, a multigene family widespread among large double-stranded DNA viruses of invertebrates and bacteria. J Gen Virol. 2003;84(Pt 9):2531-44

45. Kuzio J, Pearson MN, Harwood SH, Funk CJ, Evans JT, Slavicek JM, et al. Sequence and analysis of the genome of a baculovirus pathogenic for Lymantria dispar. Virology. 1999;253(1):17-34.

46. Harrison RL, Bonning BC. Comparative analysis of the genomes of Rachiplusia ou and Autographa californica multiple nucleopolyhedroviruses. J Gen Virol. 2003;84(Pt 7):1827-42.

47. Hashimoto $Y$, Hayakawa T, Ueno Y, Fujita T, Sano Y, Matsumoto T. Sequence analysis of the Plutella xylostella granulovirus genome. Virology. 2000;275(2):358-72.

48. Ohkawa T, Rowe AR, Volkman LE. Identification of six Autographa californica multicapsid nucleopolyhedrovirus early genes that mediate nuclear localization of G-actin. J Virol. 2002;76(23):12281-9.

49. Rohrmann G: The AcMNPV genome: Gene content, conservation and function In: Baculovirus Molecular Biology, Third edition. Bethesda (MD): National Center for Biotechnology Information (US), 2013.

50. Haas AL, Katzung DJ, Reback PM, Guarino LA. Functional characterization of the ubiquitin variant encoded by the baculovirus Autographa californica. Biochemistry. 1996;35(17):5385-94.

51. van Strien EA, Jansen BJ, Mans RM, Zuidema D, Vlak JM. Sequence and transcriptional analysis of the ubiquitin gene cluster in the genome of Spodoptera exigua nucleopolyhedrovirus. J Gen Virol. 1996;77(Pt 9):2311-9.

52. Braunagel SC, He H, Ramamurthy P, Summers MD. Transcription, translation, and cellular localization of three Autographa californica nuclear polyhedrosis virus structural proteins: ODV-E18, ODV-E35, and ODV-EC27. Virology. 1996;222(1):100-14.

53. Oliveira JV, de Brito AF, Braconi $C T$, de Melo Freire CC, lamarino A, de Andrade Zanotto PM. Modularity and evolutionary constraints in a baculovirus gene regulatory network. BMC Syst Biol. 2013;7:87.

54. Vanarsdall AL, Pearson MN, Rohrmann GF. Characterization of baculovirus constructs lacking either the Ac 101, Ac 142, or the Ac 144 open reading frame. Virology. 2007;367(1):187-95.

55. Belyavskyi M, Braunagel SC, Summers MD. The structural protein ODV-EC27 of Autographa californica nucleopolyhedrovirus is a multifunctional viral cyclin. Proc Natl Acad Sci U S A. 1998;95(19):11205-10.

56. Nai YS, Wu CY, Wang TC, Chen YR, Lau WH, Lo CF, et al. Genomic sequencing and analyses of Lymantria xylina multiple nucleopolyhedrovirus. BMC Genomics. 2010;11:116.

57. van Houte S, Ros V, Mastenbroek TG, Vendrig NJ, Hoover K, Spitzen J, et al. Protein tyrosine phosphatase-induced hyperactivity is a conserved strategy of a subset of baculoviruses to manipulate lepidopteran host behavior. PLoS One. 2012;7(10):e46933.

58. Hoover K, Grove M, Gardner M, Hughes DP, McNeil J, Slavicek J. A gene for an extended phenotype. Science. 2011;333(6048):1401.

59. Kamita SG, Nagasaka K, Chua JW, Shimada T, Mita K, Kobayashi M, et al. A baculovirus-encoded protein tyrosine phosphatase gene induces enhanced locomotory activity in a lepidopteran host. Proc Natl Acad Sci U S A. 2005;102(7):2584-9.

60. Katsuma S, Koyano Y, Kang W, Kokusho R, Kamita SG, Shimada T. The baculovirus uses a captured host phosphatase to induce enhanced locomotory activity in host caterpillars. PLoS Pathog. 2012;8(4):e1002644.

61. O'Reilly DR. Auxiliary genes of baculoviruses. In: Miller LK, editor. The baculoviruses. New York: Springer Science + Busiess Media, LLC; 1997. p. 273-6.

62. Clem RJ, Passarelli AL. Baculoviruses: sophisticated pathogens of insects. PLoS Pathog. 2013;9(11):e1003729.

63. Delcher AL, Bratke KA, Powers EC, Salzberg SL. Identifying bacterial genes and endosymbiont DNA with Glimmer. Bioinformatics. 2007;23(6):673-9.

64. Borodovsky M, McIninch J. GeneMark: parallel gene recognition for both DNA strands. Comput Chem. 1993;17(2):123-33.

65. Rice P, Longden I, Bleasby A. EMBOSS: The European Molecular Biology Open Software Suite. Trends Genet. 2000;16(6):276-7.

66. Finn RD, Clements J, Eddy SR. HMMER web server: interactive sequence similarity searching. Nucleic Acids Res. 2011;39(Web Server issue):W29-37.

67. Lupas A, Van Dyke M, Stock J. Predicting coiled coils from protein sequences. Science. 1991;252(5009):1162-4.

68. Kall L, Krogh A, Sonnhammer EL. A combined transmembrane topology and signal peptide prediction method. J Mol Biol. 2004;338(5):1027-36. 
69. Benson G. Tandem repeats finder: a program to analyze DNA sequences. Nucleic Acids Res. 1999;27(2):573-80.

70. Kraemer L, Beszteri B, Gabler-Schwarz S, Held C, Leese F, Mayer C, et al. STAMP: Extensions to the STADEN sequence analysis package for high throughput interactive microsatellite marker design. BMC bioinformatics. 2009;10:41.

71. Tamura K, Stecher G, Peterson D, Filipski A, Kumar S. MEGA6: Molecular evolutionary genetics analysis version 6.0. Mol Biol Evol. 2013;30(12):2725-9.

72. Katoh K, Misawa K, Kuma K, Miyata T. MAFFT: a novel method for rapid multiple sequence alignment based on fast Fourier transform. Nucleic Acids Res. 2002;30(14):3059-66.

73. Le SQ, Gascuel O. An improved general amino acid replacement matrix. Mol Biol Evol. 1993;25(7):1307-20.

74. Tamura K, Battistuzzi FU, Billing-Ross P, Murillo O, Filipski A, Kumar S. Estimating divergence times in large molecular phylogenies. Proc Natl Acad Sci U S A. 2012;109(47):19333-8.

75. Darling ACE, Mau B, Blattner FR, Perna NT. Mauve: Multiple alignment of conserved genomic sequence with rearrangements. Genome Res. 2004;14(7):1394-403.

\section{Submit your next manuscript to BioMed Central and take full advantage of:}

- Convenient online submission

- Thorough peer review

- No space constraints or color figure charges

- Immediate publication on acceptance

- Inclusion in PubMed, CAS, Scopus and Google Scholar

- Research which is freely available for redistribution 